\title{
APHIS, FDA, and NIH issue memorandum of understanding on laboratory animal welfare
}

On 1 March 2006, the US Department of Agriculture Animal and Plant Health Inspection Service (USDA APHIS), the US Food and Drug Administration (FDA), and the National Institutes of Health (NIH) published a memorandum of understanding concerning laboratory animal care and welfare ${ }^{1}$.

Each of these agencies has responsibilities for the promotion of proper care and use of research animals. In their memorandum of understanding, which will help in the promotion of laboratory animal welfare, USDA APHIS, FDA, and NIH agreed to share information of mutual concern and interest regarding animal welfare as follows:

- "The cooperating agencies agree to share information contained in their respective registries/inventories/listings of organizations that fall under their purview.

- "The cooperating agencies agree to provide one another with information concerning significant adverse findings regarding animal care and use at organizations investigated, inspected, or site-visited, and the actions taken by the agency in response to the findings.

- "The cooperating agencies agree to provide one another with information regard- ing evidence of serious noncompliance with required standards or policies for the care and use of laboratory animals at organizations that fall under the authority of the participating agencies.

- "The cooperating agencies agree, to the extent possible, to coordinate successive evaluations and to avoid redundant evaluations of the same entities.

- "The cooperating agencies agree to consult and coordinate with each other on regulatory or policy proposals and significant policy interpretations involving animal care and use under consideration by each agency.

- The cooperating agencies agree to provide each other with resource persons for scientific and educational seminars, speeches, and workshops related to laboratory animal welfare.

- "The cooperating agencies agree to limit the dissemination of shared information received to internal agency officials that have a need to know. If a cooperating agency receives a Freedom of Information Act request for records provided by another agency, the recipient agency will refer the request to the agency that provided the records. The recipient agency shall prompt- ly notify the agency that provided the information of any judicial order that compels the release of information ${ }^{1}$."

The agreement is effective for five years, but can be terminated by any of the three participating parties with 90-day written notice.

1. Memorandum of understanding among the Animal and Plant Health Inspection Service U.S. Department of Agriculture and the Food and Drug Administration U.S. Department of Health and Human Services and the National Institutes of Health U.S. Department of Health and Human Services concerning laboratory animal welfare. (1 March 2006). http://grants.nih.gov/grants/ olaw/references/finalmou.htm. 